\title{
EDITORIAL
}

\section{A importância da acreditação para instituições de saúde}

A avaliação externa dos sistemas de saúde é cada vez mais utilizada em todo o mundo para regular e melhorar a prestação de cuidados de saúde.

A revisão por pares e a acreditação, avalia as relações da estrutura organizacional através de critérios de excelência. São programas independentes e voluntários desenvolvidos a partir de um enfoque de avaliação multidisciplinar de cuidados em saúde.

Os modelos de acreditação disponíveis são executados por agencias independentes, credenciadas por padrões internacionais. A evolução dos modelos e mecanismos de avaliação externa da qualidade, quando bem-sucedidos envolvem os usuários, profissionais, compradores e governos no estabelecimento de padrões e definições de políticas.

É sabido que modelos de acreditação bem implementados, envolvem todas as partes interessadas na busca de informações mais detalhadas para a melhoria da eficiência, qualidade, desempenho e incentivo a inovação.

Para sustentar a excelência, os modelos de acreditação estabelecem dois focos centrais. 0 primeiro deles voltado a estrutura de uma governança eficaz, apta e preparada em fornecer supervisão e suporte com uma comunicação assertiva, objetiva e eficaz. A outra, refere- se a estruturas robustas de educação e orientação de segurança e qualidade para todos os colaboradores.

Os programas de acreditação têm sido amplamente implementados, sendo considerados ferramentas essenciais de melhoria da qualidade. Existem evidências consistentes de que esses programas melhoram o processo de atendimento prestado pelos serviços de saúde e melhoram os resultados clínicos de um amplo espectro de condições clínicas.

Os programas de acreditação devem ser apoiados como uma ferramenta para melhorar a qualidade dos serviços de saúde.

Mara Machado

Chief Knowledge Officer

IQG - Health Services Accreditation 